\title{
THREE-DIMENSIONAL MODEL PRINTING IN ORAL AND MAXILLOFACIAL RECONSTRUCTIVE SURGERY: COMPARISON OF THREE-DIMENSIONAL MODELS AND MULTISLICE COMPUTED TOMOGRAPHY SCANS
}

\author{
ADHITYA LATIEF ${ }^{1 *}$, PRADONO SUHARDI ${ }^{1}$, CHOLID BADRI ${ }^{2}$ \\ ${ }^{1}$ Department of Oral and Maxillofacial Surgery, Faculty of Dentistry, Universitas Indonesia. ${ }^{2}$ Laboratory of Biomedical Technology, Faculty \\ of Post-Graduate Programs, Universitas Indonesia. Email: adhityalatief@yahoo.com
}

Received: 16 September 2017, Revised and Accepted: 3 October 2017

ABSTRACT

Objective: The objective of this study is to compare fabrication of commonly used three-dimensional (3D) models with original multislice computed tomography (MSCT) scan data for accuracy and precision in reconstruction surgery.

Methods: MSCT data from 10 samples are processed and manufactured to be 3D models. Both groups are then measured and analyzed for the purpose of comparison.

Results: The average mandibular measurement difference between 3D models and MSCT scans is $0.26 \mathrm{~mm}$ more $<2 \%$. The final results of the comparison reveal high accuracy in 3D models compared to MSCT scan data.

Conclusion: The 3D model could be considered as surgical guidance for maxillofacial reconstruction surgery since it yields highly accurate results.

Keywords: Three-dimensional model, Computer-aided design, Reconstructive surgery.

(C) 2017 The Authors. Published by Innovare Academic Sciences Pvt Ltd. This is an open access article under the CC BY license (http://creativecommons. org/licenses/by/4. 0/) DOI: http://dx.doi.org/10.22159/ijap.2017.v9s2.18

\section{INTRODUCTION}

Corrective and reconstructive cranio-maxillofacial interventions are a challenging area of surgery that requires careful pre-operative planning [1]. To accommodate the need for precision pre-operative planning, surgeons frequently need guidance such as a threedimensional (3D) model to display complex cranial structures [2,3]. Over the past decade, 3D models have been employed widely in maxillofacial surgery [4]. This has tended to concentrate on the reproduction of exact physical replicas of patients' skeletal anatomy, which surgeons and prosthetic experts use to help plan reconstructive surgery and prosthetic rehabilitation [5].

A 3D model is a manufactured model made by a 3D printer using digital imaging and communication for medicine (DICOM) data from a computed tomography (CT) scan, and then, converted into computer-assisted design (CAD) data [3,4-7]. To illustrate an example of a 3D model, Fig. 1 presents a model that was produced with a fused deposition material (FDM) printer using polymer materials which are extruded by a printer nozzle and built layer-by-layer into a structured model [3]. A 3D model can be used as a real-size measurement and simulate a reconstruction plate that will be used in surgery as shown in Fig. 2 [4].

These models can then be used for pre-operative planning, education, and surgical simulation purposes such as locating osteotomy lines or even standard reconstructive plates, and other appliances can be prebent using a medical model, so they can thereby significantly reduce operating time. Several methods could be used to make a 3D model using selective laser sintering (SLS), 3D printing (3DP), FDM and Polyjet technologies [8,9]. FDM is one of the techniques used for 3DP.

FDM works on an "additive" principle by laying down material in layers; a plastic filament or metal wire is unwound from a coil and supplies material to produce a part $[10,11]$. FDM begins with a software process which processes a stereolithography (STL) file format, mathematically slicing and orienting the model for the build process. If required, support structures may be generated. The machine may dispense multiple materials to achieve different goals, for example, one can use one material to build up the model and use another as a soluble support structure, or one could use multiple colors of the same type of thermoplastic on the same model, as shown in Fig. $3[10,12]$.

At our center, the Department of Oral and Maxillofacial Surgery, at Universitas Indonesia, we regularly produce models using a CAD software for DICOM data analysis and an FDM printer, since this method is widely used because of the availability of materials and printers and lower production costs $[13,14]$.

Currently, there is no gold standard for the accuracy measurements of medical models compared to the accuracy of multislice CT (MSCT) device and 3D models produced using FDM printers for the imaging of anatomical structures. When a 3D model from facial structures is created using tomography images, it can be unreliable because of the partial volume effects that occur during the imaging (Lamecker et al., 2007).

Furthermore, the thin walls of the cavities in the skull tend to disappear during the imaging. Mallepree and Bergers (2009) reported on the accuracy of a conversion from CT images to 3D reconstruction and found that the accuracy varied between conversion parameters $[8,15]$. A complete scheme of model processing can be seen in Fig. 4 which shows how data from a CT scan can end up as a 3D model.

The accuracy of medical models varies between different materials, technologies of 3D models, and the type of machine used. This important aspect has not been investigated sufficiently, although medical applications of 3D models have been recently widely reported in cranio-maxillofacial surgery. Further, the requirements for the accuracy criteria depend on each application type $[3,8]$. The aim of this 

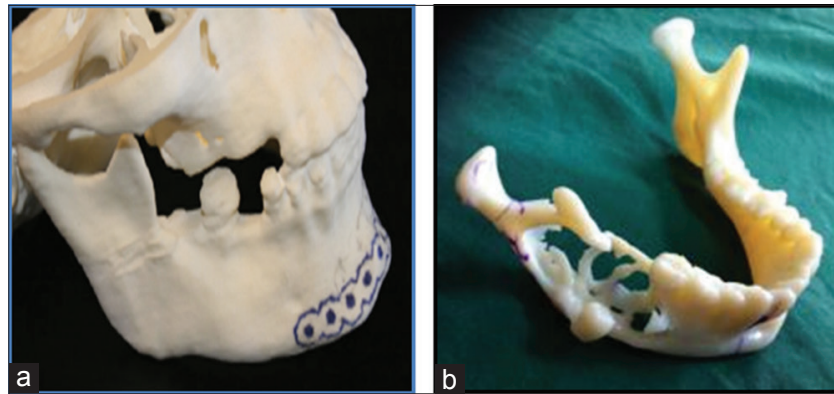

Fig. 1: (a and b) Example of three-dimensional model made using fused deposition material (FDM) technology with original source data from an multislice computed tomography scan and processed into stereolithography data to be printed using software and produced using an FDM printer [3]
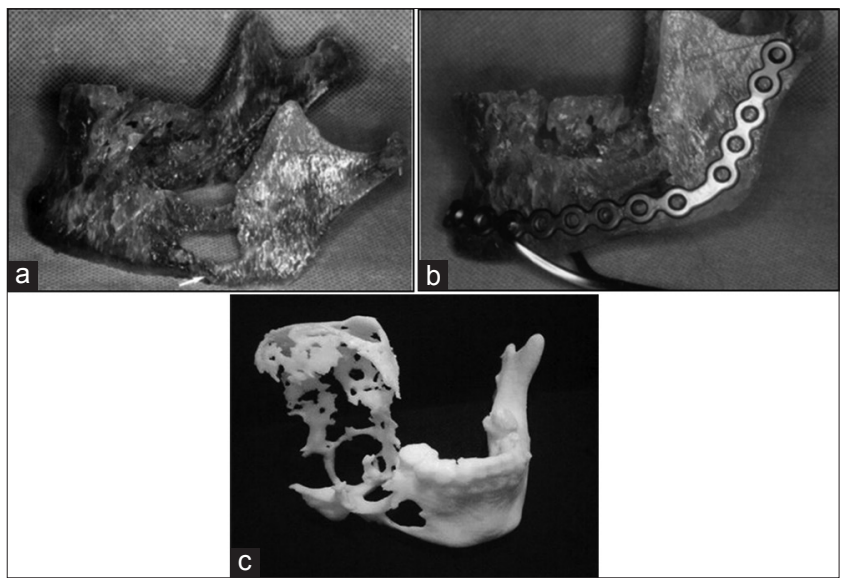

Fig. 2: Application of three-dimensional model as guidance in pre-bending reconstruction plate, as a study model for deciding length, size, holes of reconstruction plate, to decide tumor margin and free tumor margin. (a) A mandibular model with a defect in the left posterior corpus, after deciding tumor and cutting margin [4], (b) bended reconstruction plate based on the previous model [4], (c) larger defect in one side of mandible goes through to the condyle area

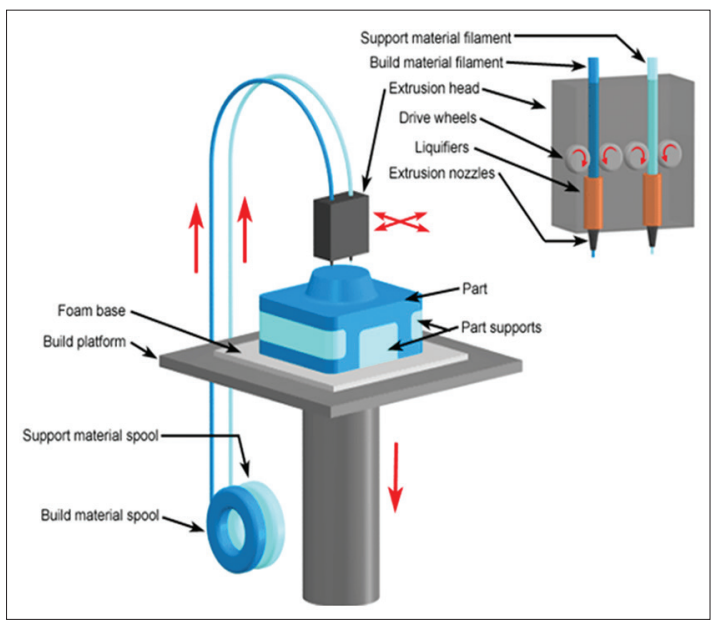

Fig. 3: Fused deposition material printing machine diagram. Build material (polymer ABS) is inserted into the nozzle, which is heated and intruded to create and build a structure layer by layer. There are two types of structures, namely, a support structure and a model structure. The printer machine works continuously from the bottom until the top layer is completely formed study was to yield more information about the accuracy of commonly used 3D models and to compare these results with CT scan data as well as existing literature.

\section{METHODS}

All samples are from patients' data from the OMS Department at Universitas Indonesia, and all patients were scanned using a CT scan machine (MSCT Somatom Definition AS+ 128 Slice Dual Source, SIEMENS, Germany) in CiptoMangunkusumo Hospital, Jakarta. Every piece of data has to fulfill criteria which exclude or include certain parameters, namely, the patient is an adult (age 18-35), there are no defects in the symphysis region nor any fractures, teeth in the anterior region of the mandible are still intact, and there are no pathological conditions in the symphysis area of the mandible. Selection concludes 10 samples of DICOM patient data which fit the criteria to be used. The data samples are then processed at the Biomedical Technology Laboratory, Post-Graduate Faculty, Universitas Indonesia, Jakarta.

Each sample is then converted into STL data using OSIRIX software (OSIRIX MD 64-Bit, Pixmeo SARL, Geneva, Swiss) without any modification of preliminary data retrieved. The OSIRIX software shown in Fig. 5 is MSCT scan viewer software that could be installed using any MacOs computer. The STL data are then prepared for print using a printing processing software (CATIA V6 2013x by Dassault, 2012, France) and manufactured using FDM 3DP machine (uPrint Plus by Dimension, Stratasys, 2012, U.S). The printing materials use ABS (Acrylonitrile Butadiene Styrene) polymer for models and support model FDM printer materials.

Each model produced is measured by marking the measurement point for symphysis mandible height (crestal-midline menton) and symphysis mandible thickness (pogonion-midline lingual), using digital calibrated electronic caliper (STARRET, EC799A-8/200 Electronic Caliper, Stainless Steel., 0005" Resolution, 0-8” Measuring Range, 2015, Massachusetts, U.S) for each model measured. For digital data, using OSIRIX MD 64 Bit, each piece of data is measured with the same measurement point.

All pieces of data are measured by two observers, and a Duplo measurement is done for each sample. Fig. 6. shows how digital marking was obtained from the axial, coronal, and sagittal positions and confirmed by its position in 3D imaging. After the distance is measured digitally, measurement in the model is obtained based on the same anatomical landmark point that is used in digital measurement as shown in Fig. 7.

This research is approved as Exempted Research by the Ethical Committee Research Faculty of Dentistry, Universitas Indonesia.

\section{RESULTS}

Measurement for mandible symphysis thickness

An average summary from 10 samples, using Duplo measurement method, which is done by both observers compares a measurement from CT scan data, and the 3D model is presented in a table and charts. Table 1 represents the measurement of the symphysis mandible thickness, both from a 3D model and CT scan data; each piece of data was collected and count for the average rate to be compared in each sample as a percentage.

The difference within each average sample measurement can be illustrated in a graph as shown in Fig. 6. There is slight difference within each sample compared. The results of measurement from both data sources showed that every 3D model sample has a smaller size measure compared to CT scan data, with the average difference being $0.26 \mathrm{~mm}$ or $1.85 \%$ smaller.

Measurement for symphysis mandible height

Table 2 represents the measurement of symphysis mandible height both from the 3D model and CT scan data, with each of data collected and 


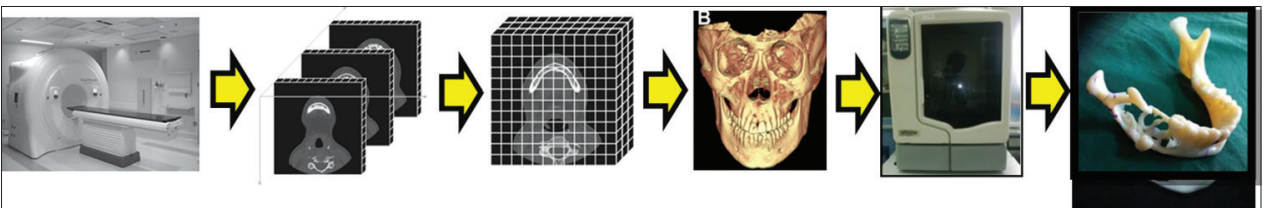

Fig. 4: Processing computed tomography (CT) scan data. Data from a CT scan contain thousands of multiple slice scans of anatomy. The data are then processed as three-dimensional (3D) imaging as digital imaging and communication for medicine (DICOM) data. The next step is to convert DICOM data in stereolithography data using digital software such as OSIRIX, which is then ready to be processed for printing. The printing process uses an fused deposition material printer that will build a model layer-by-layer. The end result is a 3D model made from ABS polymer materials with high precision
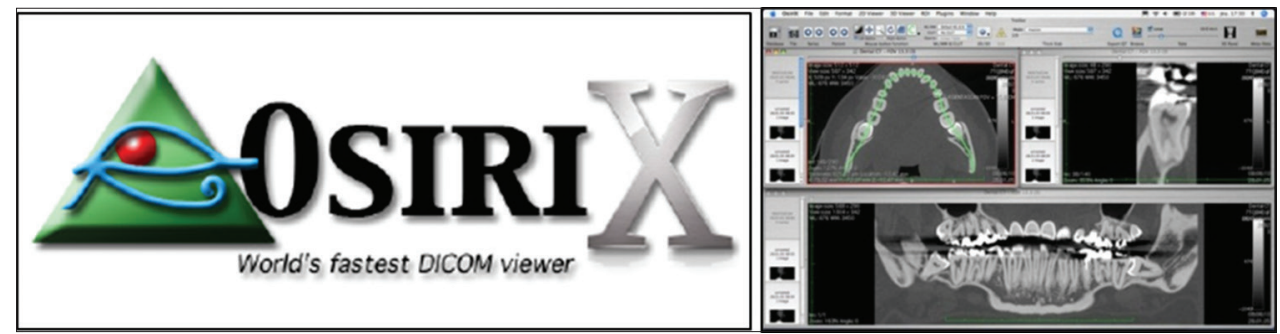

Fig. 5: OSIRIX MD 64-bit software for digital imaging and communication for medicine (DICOM)/stereolithography viewer. A common computed tomography (CT) scan viewer on the market that can read almost all CT scan data as long as the file is in DICOM format [19]

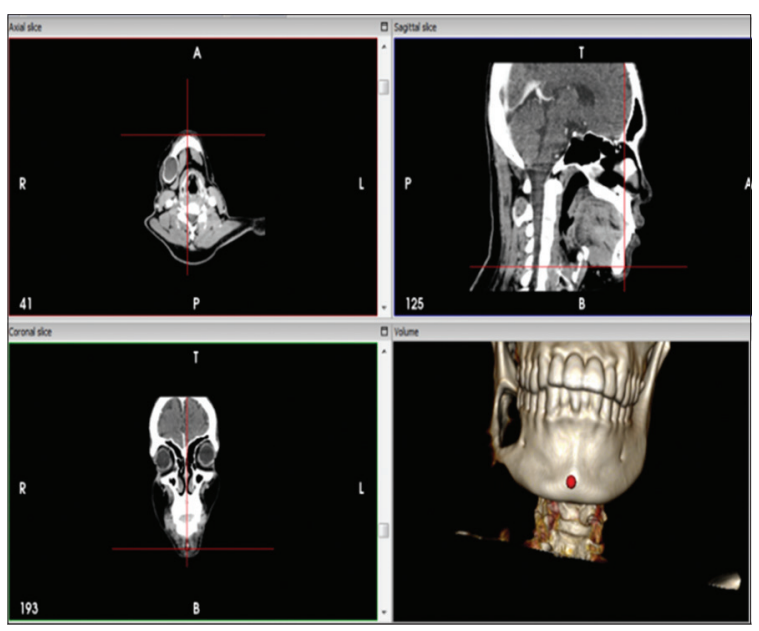

Fig. 6: Analyzing and determining the measurement point on digital software. The measurement point is obtained by determining the anatomical landmark pointed on the axial, sagittal, and coronal positions and confirmed in threedimensional view data at the same time
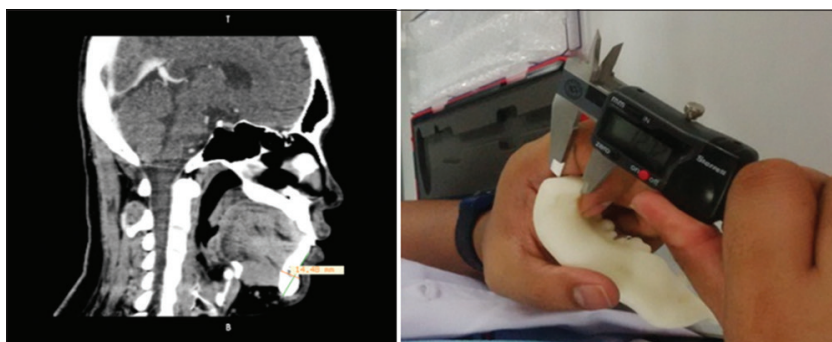

Fig. 7: Measurement of computed tomography scan data. Using measurement digital tools $(\mathrm{mm})$ and measurement in a three-

dimensional model using a digital caliper $(\mathrm{mm})$. The same anatomical landmark is pointed and measured point to point as a marking

summarized for the average and then to be compared in each sample as a percentage. The data collected has a different average percentage if compared with mandibular thickness. With a range from $0.13 \%$ to $1.37 \%$ differential between the 3D model and CT scan data.

Fig.7 shows that there is only a slight difference in each sample compared. The results of measurement from both data sources show that every 3D model sample has a smaller size measure compared to CT scan data, with the average difference being $0.26 \mathrm{~mm}$ or $0.76 \%$ smaller.

There is only a slight difference between CT scan data and the 3D model in each sample.

However, the same results of comparison measures of mandible symphysis height from both data sources also showed that every 3D model sample has a smaller size measure compared to CT scan data. There is a deviation between measurement in the 3D model where results reveal a smaller data amount compared to CT scan data. There is a variety of the different rate, which is $1.85 \%$ for the symphysis mandible thickness, which means the accuracy of the 3D model is $98.15 \%$ of the CT scan data. Meanwhile, for comparison of symphysis mandible height, there is a difference, rating $0.76 \%$ smaller in the 3D model, which means the accuracy of the 3D Model is $99.24 \%$ of the original CT scan data.

\section{DISCUSSION}

In this research, CT scan data are used as a gold standard parameter for evaluation. The previous research by Stull et al. about accuracy and reliability measurement from CT scan data compared to dry skull reveals that CT scan data could be accepted and used as an alternative in measurement [16]. Although there is a difference value between measurement in the 3D model and CT scan data on symphysis of the mandible, this result accords with previous research by Reinbacher et al. which compared the 3D model and CT scan/magnetic resonance imaging (MRI) with regard to maxillofacial bone distance. In this research, there are differences regarding measurement $[2,17]$

The mean difference is $0.26 \pm 0.17 \mathrm{~mm}$ and $0.26 \pm 0.14 \mathrm{~mm}$ for symphysis thickness and symphysis height, a result that was confirmed by previous research by El-Katatny (2010), which compared the 3D model and 3D digital imaging with a difference value of $0.22 \pm 0.11 \mathrm{~mm}$ from original CT scan data sources. Research by Choi et al. (2012) had similar results, i.e., $0.62 \pm 0.35 \mathrm{~mm}[11]$. 
Table 1: Summary of average measurement for symphysis mandible thickness

\begin{tabular}{|c|c|c|c|c|c|}
\hline No & Sample & $\begin{array}{l}\text { Average CT scan } \\
\text { horizontal }(\mathrm{mm})\end{array}$ & $\begin{array}{l}\text { Average 3D model } \\
\text { horizontal (mm) }\end{array}$ & $\begin{array}{l}\text { Average } \\
\text { different (mm) }\end{array}$ & $\begin{array}{l}\text { Percentage of } \\
\text { different }\end{array}$ \\
\hline 1 & Sample 1 & 14.60 & 14.34 & 0.26 & 1.78 \\
\hline 2 & Sample 2 & 14.45 & 14.18 & 0.27 & 1.87 \\
\hline 3 & Sample 3 & 14.62 & 14.48 & 0.14 & 0.96 \\
\hline 4 & Sample 4 & 12.90 & 12.63 & 0.27 & 2.09 \\
\hline 5 & Sample 5 & 14.74 & 14.28 & 0.46 & 3.12 \\
\hline 6 & Sample 6 & 14.15 & 13.50 & 0.65 & 4.59 \\
\hline 8 & Sample 8 & 13.60 & 13.43 & 0.17 & 1.25 \\
\hline 9 & Sample 9 & 16.28 & 16.10 & 0.18 & 1.11 \\
\hline 10 & Sample 10 & 13.77 & 13.56 & 0.21 & 1.52 \\
\hline Average summary & & 14.21 & 13.95 & 0.26 & 1.85 \\
\hline
\end{tabular}

CT: Computed tomography, 3D: Three-dimensional

Table 2: Summary of average measurement for mandible symphysis height

\begin{tabular}{|c|c|c|c|c|c|}
\hline No & Sample & Average CT - scan vertical (mm) & Average 3D model vertical (mm) & $\begin{array}{l}\text { Average } \\
\text { different }(\mathrm{mm})\end{array}$ & $\begin{array}{l}\text { Different } \\
\text { percentage }\end{array}$ \\
\hline 1 & Sample 1 & 33.48 & 33.25 & 0.23 & 0.69 \\
\hline 2 & Sample 2 & 34.93 & 34.75 & 0.18 & 0.51 \\
\hline 3 & Sample 3 & 37.50 & 37.05 & 0.45 & 1.20 \\
\hline 4 & Sample 4 & 35.24 & 35.02 & 0.22 & 0.62 \\
\hline 5 & Sample 5 & 41.07 & 40.98 & 0.09 & 0.22 \\
\hline 6 & Sample 6 & 30.65 & 30.23 & 0.42 & 1.37 \\
\hline 8 & Sample 8 & 30.80 & 30.76 & 0.04 & 0.13 \\
\hline 9 & Sample 9 & 36.41 & 36.09 & 0.32 & 0.88 \\
\hline 10 & Sample 10 & 36.54 & 36.09 & 0.45 & 1.23 \\
\hline Average summary & & 34.80 & 34.53 & 0.26 & 0.76 \\
\hline
\end{tabular}

CT: Computed tomography, 3D: Three-dimensional

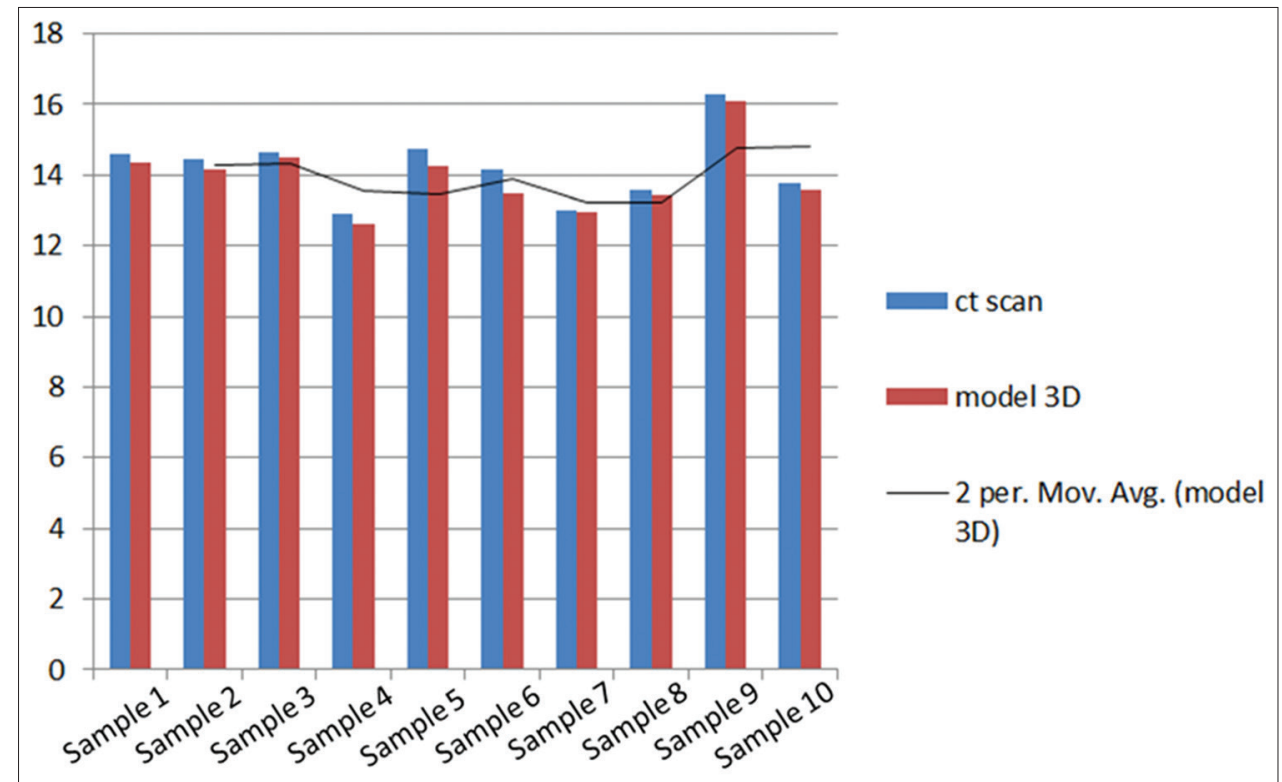

Fig. 8: Chart diagram for average measurement of symphysis mandible thickness. All samples show that there are slightly less data in the three-dimensional model compared to computed tomography scan data

To prevent deviation of size or deciding a different measure point in each measurement, several previous studies (Pfeifer et al., 2001; Bauza et al., 2005; Hansen et al., 2006; Weckenmann et al., 2006) suggested using the Coordinative Surveying Procedure (CSP) which is commonly used in the 3D industry because the accuracy of it is up to $1 / 1000 \mathrm{~mm}$ and can measure linear or non-linear surfaces. Meanwhile, in this research, a digital caliper is used for measurement, which only has an accuracy of $1 / 100 \mathrm{~mm}$; it has already been used in research by Olszewski et al. $[9,2]$.
According to Olszewski et al., the comparison between 3D model and CT scan data or 3D model and dry skull, in each pair, has different accuracy value. Since there is no gold standard for the accuracy of 3D models, evaluation of measurement will be variative [9]. Nizam stated that measurement using a 3D model should be done using two measuring points that are far enough from each other, i.e. more than $50 \mathrm{~mm}$, so that the deviation could decrease further, and the final result will yield better accuracy [17]. Olszewski et al. also suggest that deviation value should not be a parameter for accuracy in further research, but 


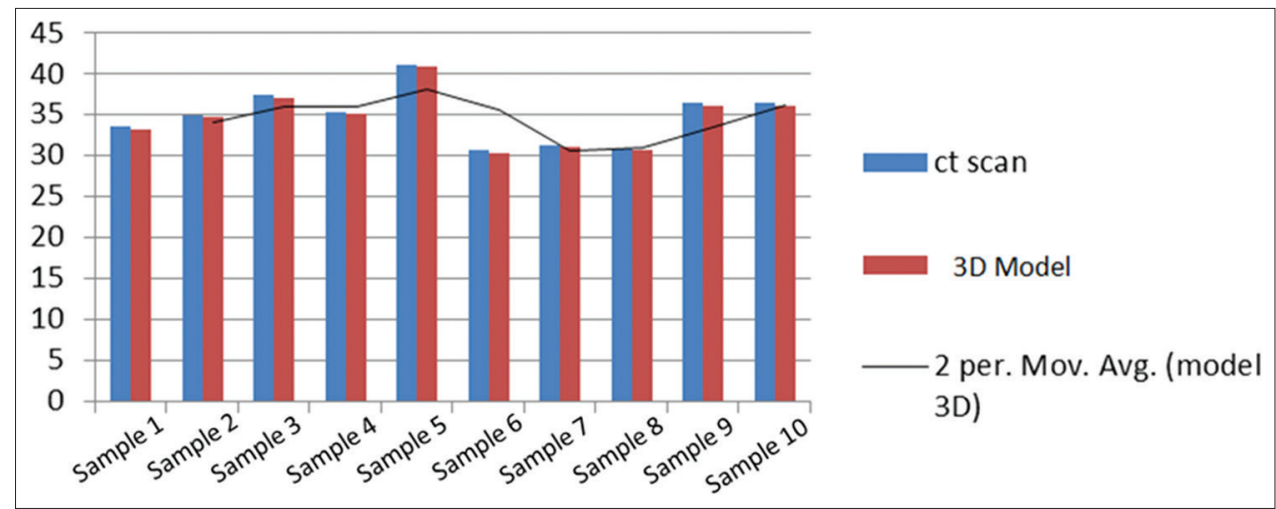

Fig. 9: Chart of average measurement for symphysis mandible height

it can still be used if a correct and appropriate method is utilized for measurement [9].

\section{CONCLUSION}

Measurement in all 3D samples leads to the conclusion that there is a smaller data value compared to CT scan data value. The average difference is $0.26 \mathrm{~mm}$ whether in height or thickness of the symphysis mandible. This means that the 3D model produced has an accuracy of more than $98 \%$ than its original size. Although in statistic value is different, clinically the difference is very small between CT scan data and the 3D model of the symphysis mandible, so its use could be considered in clinical practice or as surgical guidance in reconstruction surgery.

The use of 3D models will become more accurate and precise due to the advancement of technology. Surgeons should become more aware of and benefit from this technological advancement since it is useful, especially with reconstructions.

\section{ACKNOWLEDGMENT}

The authors wish to thank Prof. Benny Latief, Department of Oral and Maxillofacial Surgery, Universitas Indonesia, for his contribution to explore ideas about surgery planning that lead author to do further study in 3D model for pre-operative planning.

The publication of this manuscript is supported by Universitas Indonesia.

\section{REFERENCES}

1. Kaduk WM, Podmelle F, Louis PJ. Surgical navigation in reconstruction. Oral Maxillofac Surg Clin North Am 2013;25:313-33.

2. Reinbacher KE, Wallner J, Kärcher H, Pau M, Quehenberger F, Feichtinger M. Three dimensional comparative measurement of polyurethane milled skull models based on CT and MRI data sets. J Craniomaxillofac Surg 2012;40:e419-25.

3. Huotilainen E, Jaanimets R, Valášek J, Marcián P, Salmi M, Tuomi J, et al. Inaccuracies in additive manufactured medical skull models caused by the DICOM to STL conversion process. J Craniomaxillofac Surg 2014;42:e259-65.
4. Wang CS, Wang WH, Lin MC. STL rapid prototyping bio-cad model for CT medical image segmentation. Comput Ind 2010;61:187-97.

5. Essig H, Rana M, Kokemueller H, von See C, Ruecker M, Tavassol F, et al. Pre-operative planning for mandibular reconstruction-a full digital planning workflow resulting in a patient specific reconstruction. Head Neck Oncol 2011;3:45

6. Wang G, Li J, Khadka A, Hsu Y, Li W, Hu J. CAD/CAM and rapid prototyped titanium for reconstruction of ramus defect and condylar fracture caused by mandibular reduction. Oral Surg Oral Med Oral Pathol Oral Radiol 2012;113:356-61.

7. Zheng GS, Su YX, Liao GQ, Chen ZF, Wang L, Jiao PF, et al. Mandible reconstruction assisted by preoperative virtual surgical simulation. Oral Surg Oral Med Oral Pathol Oral Radiol 2012;113:604-11.

8. Salmi M, Paloheimo KS, Tuomi J, Wolff J, Mäkitie A. Accuracy of medical models made by additive manufacturing (rapid manufacturing). J Craniomaxillofac Surg 2013;41:603-9.

9. Olszewski R, Szymor P, Kozakiewicz M. Accuracy of threedimensional, paper-based models generated using a low-cost, threedimensional printer. J Craniomaxillofac Surg 2014;42:1847-52.

10. Taufik M, Jain PK. A study of build edge profile for prediction of surface roughness in fused deposition modeling. J Manuf Sci Eng 2016;138:061002-11.

11. El-Katatny I, Masood SH, Morsi YS. Error analysis of fdm fabricated medical replicas. Rapid Prototyp J 2010;16:36-43.

12. Cohen A, Laviv A, Berman P, Nashef R, Abu-Tair J. Mandibular reconstruction using stereolithographic 3-dimensional printing modeling technology. Oral Surg Oral Med Oral Pathol Oral Radiol Endod 2009;108:661-6.

13. Yamauchi T, Yamazaki M, Okawa A, Furuya T, Hayashi K, Sakuma T, et al. Efficacy and reliability of highly functional open source DICOM software (OsiriX) in spine surgery. J Clin Neurosci 2010;17:756-9.

14. Kim G, Jung HJ, Lee HJ, Lee JS, Koo S, Chang SH. Accuracy and reliability of length measurements on three-dimensional CT using open-source osirix software. J Digit Imaging 2012;25:486-91.

15. Mallepree T, Bergers D. Accuracy of medical RP models. Rapid Prototyp J 2009;15:325-32.

16. Stull KE, Tise ML, Ali Z, Fowler DR. Accuracy and reliability of measurements obtained from CT 3D volume rendered images. Forensic Sci Int 2014;238:133-40.

17. Nizam A, Gopal RN, Naing L, Hakim AB, Samsudin AR. Dimensional accuracy of the skull models produced by rapid prototyping technology using STL apparatus. Arch Orofac Sci 2006;1:60-6. 